\title{
The benefits of applying the lightning talk in child and youth care education
}

\section{Johanne Jean-Pierre, Sabrin Hassan, Jonathan Bailey, Kiaras Gharabaghi and Asha Sturge}

\section{Introduction}

Child and youth care instructors often aspire to prepare students for unforeseen circumstances in the field, including circumstances that may require spontaneous advocacy and public speaking skills in various settings, such as an interdisciplinary case conference or a plan of care meeting. We suggest that one way of contributing to these goals is the pedagogy of the lightning talk. A lightning talk can be defined as a short (three minutes), time-limited, oral presentation on a particular subject without the use of supporting materials, such as Power Point slides, notes, an electronic device, or audience engagement, so as to simulate a practice context that was unexpected and for which the practitioner has no opportunity to plan or prepare (Jean-Pierre et al., 2020). It differs from an elevator speech or pitch, which is usually expected to last less than a minute (30 to 60 seconds) and has been employed in the corporate world and other professions to sell an idea, a product, or a service (Cox \& Marris, 2011; Pagana, 2013; Simpson, 2016). The lightning talk is longer and shares similarities with the Three Minute Thesis (3MT) contest, which challenges graduate students to present their research projects in a concise and clear

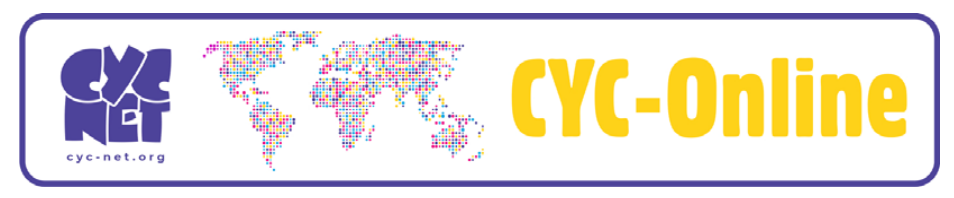

December 2021

ISSN 1605-7406 
fashion (Hu \& Liu, 2018). In this article, we will share the main lessons learned from a study that examined the learning experiences and processes of the pedagogy of the lightning talk at a Canadian metropolitan university in two child and youth care undergraduate courses. After a close examination of the main findings, our research team realized that the lightning talk fosters meta-cognitive, public speaking and advocacy skills that prepare students to advocate spontaneously on their feet in everyday frontline practice. We furthermore realized that spontaneous advocacy skills may significantly strengthen practice unfolding with frameworks of radical youth work, critical child and youth care, or child and youth care politicized praxis. As the Standards for Practice of North American Child and Youth Care Professionals (2017) specifies, advocating for, with and onbehalf of children, youth and families is an integral part of child and youth care work and requires the mobilization of practical and concrete skills and competencies.
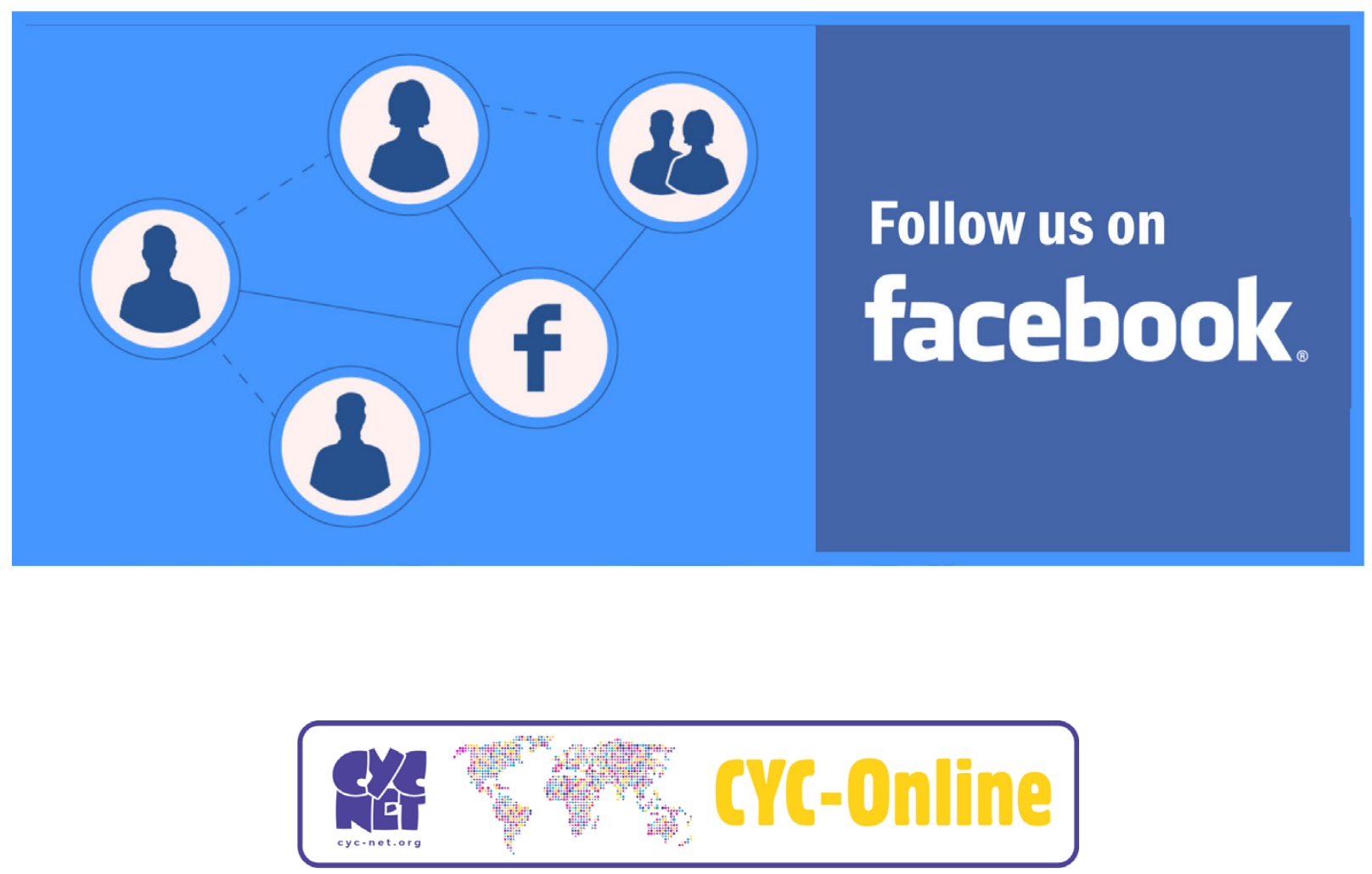

December 2021

ISSN 1605-7406 


\section{Methodology and Findings}

To conduct a study about students' learning experiences of the lightning talk, the research team obtained ethics approval from an institutional review board at a Canadian metropolitan university in 2019.

After students completed the lightning talk in two different undergraduate courses, we recruited a total of 70 participants, and they completed an online questionnaire with open-ended and closed-ended questions. Interested readers can find a complete description of the study and specific implications of the study in regard to the development of advocacy skills and public speaking skills in other articles (Jean-Pierre et al., 2020; Jean-Pierre, Hassan \& Sturge, 2021). This article presents a quick overview of what child and youth care and youth work instructors can learn about the lightning talk from an empirical study that centred the viewpoints of child and youth care undergraduate students. Here are the main takeaways from this project for instructors in our field.

\section{This activity enables students to frame, in their own words, what constitutes child and youth care work}

The lightning talk can be used to encourage students to synthesize their knowledge and frame, in their own words, what constitutes child and youth care practice. Some students focused greatly on individual characteristics and very broad skills during their lightning talks, while others were able to articulate child and youth care-specific characteristics. For instance, collaborating with colleagues in a multidisciplinary team and "meeting children and youth where they are at" are frontline principles often shared with other human services professionals. Students are encouraged really to think about the profession, their abilities, and experiences, and how they can position themselves as providing a unique

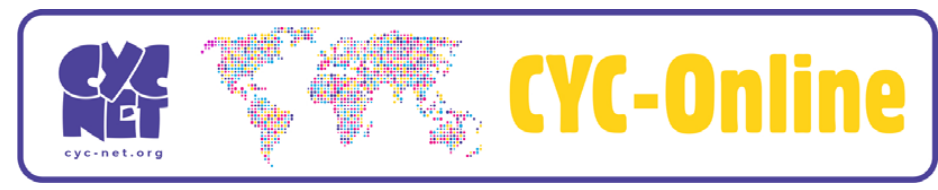

December 2021

ISSN 1605-7406 
input in the institution. The various descriptions of the profession that we heard in class may reflect contemporary debates regarding the breadth and depth of what defines and constitutes child and youth care practice (Farrell, 2018).

\section{It is important to give space for individual presentations such as the lightning talk to enable each student thoroughly to cultivate their personal skills at their own pace}

Group assignments are frequently assigned in child and youth care programs with the support of Power Point slides, notes, memos and laptops. Groups can also be required to submit a collective paper related to a presentation in order to foster communication and collaboration among future professionals. However, even with pedagogical strategies and incentives to encourage all group members to contribute to such group work projects equally, several factors can lead to one or more students dominating a group presentation and, as a result, gaining more experience in public speaking. The lightning talk-an individual, brief, oral presentation-genuinely provides each student the opportunity to reflect upon their own skills and knowledge, discover their own learning strategies, develop time management, organizational and stress-coping skills (Jean-Pierre et al., 2020). Just as importantly, the lightning talk allows students to confront the relational aspects of becoming the focal point in conversation with others; presentation skills are not limited to what is being said, but how students learn to use voice, tone, body language, positioning and other elements to render what they are saying credible and noteworthy for the audience, so as to have an impact on decisionmaking in team environments in which the child and youth care perspective is often seen as peripheral.

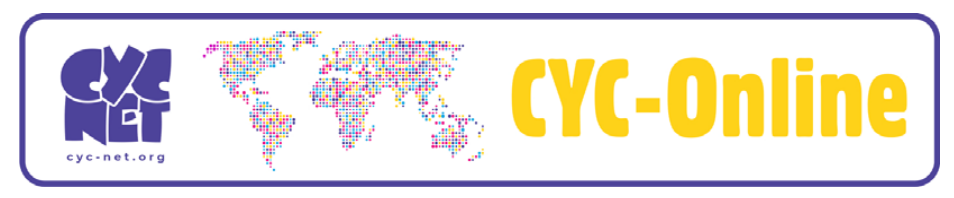

December 2021

ISSN 1605-7406 


\section{The lightning talk can facilitate the development of critical thinking skills, self-confidence, advocacy, communication, and stress management strategies}

A large proportion of students who enroll in child and youth care programs aspire to work in direct practice across human and social services. In these settings, there is an expectation that our graduates have self-confidence, as well as critical thinking, advocacy, communication and stress management skills. Through the participants' narratives, we found that the lightning talk fostered these aforementioned skills (Jean-Pierre et al., 2020) which are imperative in any professional capacity. It also became apparent that some students need to further develop their public speaking skills, while others happily discovered that they were more capable than they initially thought. Most postsecondary institutions stress in their mission statement, goals, and strategic plans how they value critical thinking and communication skills. The lightning talk can promote the development of professional competencies that prepare for everyday frontline work and nurture valued higher education learning goals.

\section{There is a need in child and youth care education to conceptualize "in the moment, think-on-your-feet advocacy" as an everyday practice that all practitioners should develop}

While there are institutions dedicated to advocacy, and several socialpolitical theories delve into equity and social change, it is important that students grasp that individual, every day, frontline work, radical youth work or child and youth care politicized praxis require a range of tangible competencies that should be fostered during pre-service education. Being able to advocate spontaneously in the workplace means engaging in frontline child and youth care work. Students should have the opportunity to learn how to identify a problem and avenues of solutions, to express

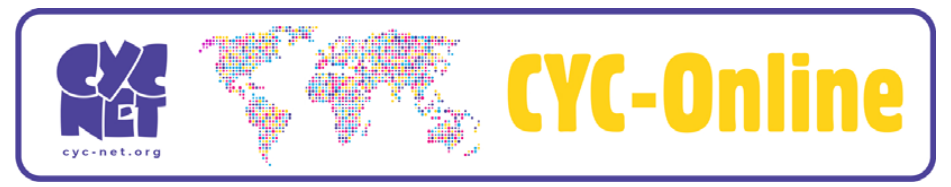

December 2021

ISSN 1605-7406 
clearly and effectively their ideas, and to think quickly on their feet.

Everyday child and youth care work can include working with children and youth that may experience several intersecting forms of marginalization which warrant that someone speak out publicly and advocate for them (or with them) in the moment, spontaneously, and in a compelling manner. It is critical that our programs' graduates be equipped with the ability to advocate orally and individually in a clear, quick, and concise manner to ensure that the children, youth, families, and communities that we work with are actually being supported.

\section{The duration of the lightning talk can be scaffolded throughout a program and can start with one minute and increase gradually in subsequent years}

We observed that the process of speaking publicly for three minutes without support of slides or other materials can be a daunting task for some students who have had fewer opportunities to develop oral presentation skills. Students in child and youth care programs can begin with one-minute lightning talks while instructors increase gradually the duration of the presentation and the learning outcomes' expectations over the years. Efforts to scaffold the lightning talk to foster oral communication skills throughout a program should be made explicit to students in order to convey that these competencies are essential for their future careers.

Overall, this research project's findings reveal that, while some students can speak publicly with ease and are poised to advocate spontaneously, other students in our programs are not yet equipped with the range of skills and competencies to do so, even when they have successfully completed a child and youth care diploma before their enrollment in a

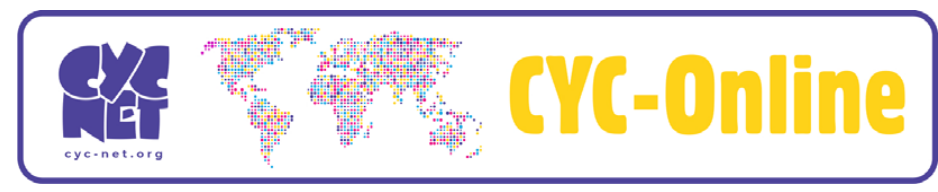

December 2021

ISSN 1605-7406 
university program. This gap can be addressed with clear, intentional, and tangible pedagogical and curricular strategic plans that aim to develop public speaking and advocacy skills. If we ignore this need, we may fall short of preparing our students to advocate for, with, and on-behalf of children, youth, families and communities. The pedagogy of the lightning talk is one of several pedagogical tools that can be used to develop advocacy skills. Thus, administrators and instructors are encouraged to imagine pedagogical tools that foster individual and group pedagogies to promote advocacy and public speaking skills development. It may not be enough to introduce students to critical or radical theories, concepts and ideas; instead, a pedagogical approach to ensure that students prepare to articulate well-integrated and compelling arguments as they encounter far-from-perfect institutional, inter-disciplinary, and often adult-centred conversations and decision-making processes in the field, is a core element of promoting not just good quality inter-personal practice, but also the real impact of child and youth care practice in the field.

\section{Conclusion}

We hope that this research project will inspire other researchers to engage in empirical studies about pedagogy and curricula that centre the experiences of all students. While accounts and reflections co-authored by instructors and students provide interesting insights, these accounts often exclude the perspectives of students who are less engaged or motivated in our programs. Despite our best efforts to develop welcoming learning environments, some students may prefer to contribute to an anonymous questionnaire rather than speak their minds in-class or during office hours. Systematic research methods enable us to capture a broader range of students' learning experiences and processes with the ethical obligation to

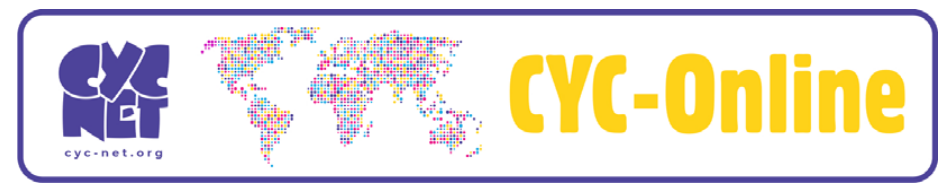

December 2021

ISSN 1605-7406 
maintain confidentiality. Child and youth care instructors and program administrators can adopt a comprehensive teaching plan throughout their program that may include the lightning talk and several other experiential and active-learning initiatives to foster critical advocacy-related competencies and skills for everyday frontline work.

\section{References}

Child and Youth Care Certification Board. (2017). Standards for Practice of North American Child and Youth Care Professionals. http://www.acycp.org/images/pdfs/ethics_and_practices_ACYCP_V2-7.pdf

Cox, A., \& Marris, L. (2011). Introducing elevator speeches in the curriculum. Journal of Education for Library and Information Science, 52(2), 133-141.

Farrell, T. (2018). In-class/after-class: conversations on the teaching and learning of relational child and youth care practice: An introduction to a new column. Relational Child and Youth Care Practice, 37(1), 23-25.

Hu, G., \& Liu, Y. (2018). Three minute thesis presentations as an academic genre: A crossdisciplinary study of genre moves. Journal of English for Academic Purposes, 35, 16-30.

Jean-Pierre, J., Hassan, S., Sturge, A., Gharabaghi, K., Lewis, M., Bailey, J., \& Panitch, M. (2020). Poised to advocate: The pedagogy of the lightning talk in child and youth care education. International Journal of Child, Youth \& Family Studies,17(3),108-125.

Jean-Pierre, J., Hassan, S., \& Sturge, A. (2021). Enhancing the learning and teaching of public speaking skills. College Teaching. (Online first), Doi: 10.1080/87567555.2021.2011705

Pagana, K. D. (2013). Ride to the top with a good elevator speech. American Nurse Today, 8(3), 1416.

Simpson, D. (2016). "Going up?" A sport psychology consultant's guide to the elevator speech. Journal of Sport Psychology in Action, 7(2), 109-120.

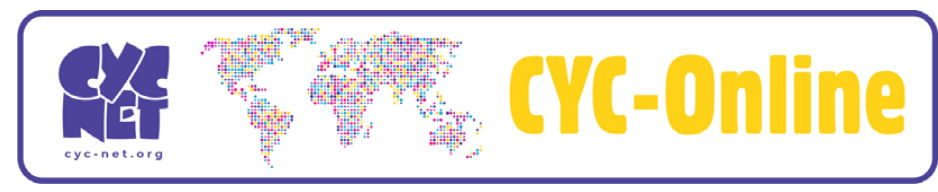

December 2021

ISSN 1605-7406 